Assiut Scientific Nursing Journal

http://asnj.journals.ekb.eg

http://www.arabimpactfactor.com

\title{
Sexual Life Pattern and Self-Care Practices Among Copper Intra Uterine Device (Iud) User At Assiut City
}

\author{
Nadia H. Ahmed ${ }^{1} \&$ Reda R. Ali ${ }^{2}$. \\ 1. Assistant professor of Maternal and Neonatal Health Nursing, Faculty of Nursing, Assiut University, Egypt. \\ 2. Lecturer of Maternal and Neonatal Health Nursing, Faculty of Nursing, Assiut University, Egypt.
}

\begin{abstract}
Background: Contraceptives as IUD method can enhance women's and public health, but may be terminated due to occurance of some problems as sexual problems and genital infection Aim: To assess self-care practices and sexual life pattern among copper IUD user at Assiut city. Methods: Descriptive research design was used, sample size convience sample involved 500 women IUD's users, study was conducted at family planning outpatient clinic, Woman's Health Hospital, and Qlta Maternal and Child Health Care center and Mabra Hospital, Eleman hosital Assiut, Egypt. Data was collected by using interview questionnaire. Results: Study shows that $67.6 \%$ of studied women have a satisfactory practices. Regarding sexual life pattern about $26 \%$ of women complain from differences in libido after using IUD, 24.4\%, 21.2\%, 23.6\%, 20.0\%, 26.8\%, and $25.8 \%$ of women have a difference in sexual desire, difficulty in vaginal wetting during cotius, difficultly reach orgasm, woman's don't satisfied at the end of sexual relationship, husband don't satisfied at the end of sexual relationship, and dysparenia respectivelly. Conclusion: IUD's users had insufficient self care practices and there have some form of sexual pattern affected by using IUD as a contraceptive method. Recommendations: Educational program about self care practices and sexual pattern for IUD users should be provided. Counselling from health care provider about self care practice
\end{abstract}

\section{Keywords: Self-Care, Practices, Sexual Life \& Copper IUD .}

\section{Introduction}

Contraceptive can improve women`s health, and so the health of the puplic, but there are some hinders that make the women to terminate their contraceptive method. From these hinders sexual problems and genital tract infection (Sanders et al., 2018) \& (Kanakannavar \& S, 2019).

Copper IUDs is one of the most widely used method in Egypt. It is reported about $52.9 \%$ of family planning users use IUDs as a contraceptive method (Egypt FP2020 Commitment, 2020). method that placed in the uterus and have two thin threats hang from the cervix. It is very effective (99\%), low cost, and long term reserviable contraceptive method that lasting from 5- 10 years (McNany, 2017).

IUDs works immediately after insertion, it release a small amount of copper. It make sperm inactive and not able to travel to fertilize egg. It also change cervical mucus to prevent sperm to reach egg.(Brown health services., 2019) IUDs is accompanied by some problems that may occur with it as heavier and longer periods, it may pushed out of the uterus, (Reproductive Heath Access, 2017).

Faulty self care practices performed during using IUDs can increase risk for vaginal infection (Baraia et al., 2017). Self care practices are individual activities performed to improve their health and well being. It can play a vital role in improving health related outcomes (Igbaria et al., 2019). Related self care practices of IUDs to avoid genital infection include personal, vaginal, menstrual and toalit hygiene (Baraia et al., 2017).

Other aspect should be taking into consideration while using IUDs as a contraceptive method, this include sexual life that should not be ignored (Umran, 2016). Female sexual dysfunction (FSD) is deficiency in at least one component of the sexual response cycle that involve desire, arousal, ability to reach orgasm and pain during sexual intercourse (Banaei et al, 2020).

It is reported that using IUDs as a contraceptive method cause lower female sexual function index (FSFI) subscale scores of desire when compared with other methods (Umran, 2016).

Women attention to the self care practices and problems which may occur while using IUDs is very important and the nurse carry the vital role to implement this action (Nurvita et al., 2018).

\section{Significant of the study}

According to WHO estimation, 160 million women use IUDs world wide ,Also IUD may be associated with lower genital tract infection (Kanakannavar \& S., 2019) In Mansoura University in 2011 a study conducted about rate of 
occurrence of vaginitis and cervicitis among IUDs users and have found 12, $6 \%$ of them develop vaginitis and 8,6\% have develop cervicitis (Ashraf, et al., 2011) and self care practices play a vital role to enhance health related outcomes (Igbaria et al., 2019), so the researcher interested in assessing self care practices and sexual pattern among IUD users. Umran 2016, who carried out their study to evaluate the effect of contraceptive method on the function of female sex, and found that around one quarter of studied women had a dyspareunia and sexual problem in partener. also. Rezk et al., (2017) assess risk of genital infection among new users of COCS and LNG-IUS, and clarified that less than one quarter of studied women had bacterial vaginosis. This difference back to using of LNG-IUS instead of copper IUDs

Aim of the study

The present study aimed to

Assess self care practices and sexual pattern among IUDs users at Assiut city

Research questions

Does the use of IUDs have an effect in sexual function?

Are Self care practice had effect on sexual life pattern among copper Intra uterine device (IUDs) users at Assiut city

Subjects and methods

Research design: Descriptive exploratory research design was carried out in this study.

Study setting: The study was conducted at family planning outpatient clinic, Woman's Health Hospital (one of the great teaching hospitals in Upper Egypt), Assiut University, Egypt and Qlta Maternal and Child health Care center and Mabra Hospital, and Eleman hosital at Arabaeen hospital. all of them serves all women from rural and urban areas.

\section{Study sample}

The sample was consist of a convenience sample 500 women attending at

a family planning method and attended to the family planning outpatient clinic of Woman's Health Hospital and Qlta Maternal and Child health Care center Mabra Hospital, and Eleman hosital at Arabaeen for follow up. (a precision of 5\%, $=0,05$ and power of $95 \%$ )

Sample size calculation

Sample size calculated through Open Epi-Info Statistical Package, Version 2.3.1 using the sample size equation. The total numbers of IUDs users were 500 women. With precision levels $5 \%$ where confidence level is $95 \%$ and $p<0.05$.

Inclusion criteria

All women who used copper IUDs as a family planning method attended to the family planning outpatient clinic and Qlta Maternal and Child health Care center Mabra Hospital, Eleman hosital at
Arabaeen for follow up and accepted to participate in the study.

Tool of the study

Structured interview questionnaire:

I:Intreviewing QuestionnaireIt was divided into five parts:

Part 1 - sociodemographic data: patient's age, level of education, occupation and resident.

Part 2- Menstrual history includes: age of menarche, duration, regularity interval and any menstrual abnormalities.

Part 3- Obstetric history which includes: gravidity, parity, type of delivery (normal, caesarian section)

Part 4 - Feminine hygiene which include: vaginal douches; spray; suppository sanitary pads, kind of under wear, technique of vaginal cleaning.

Part 5- Family Planning history which include: IUD usage duration, indications and any discomfort or complications ;(metrorrhagia, spotting, infection, gastrointestinal infection, blood loss, sexual problems and unwanted pregnancy)

Tool II - Sexual Function Scale: Which include sexual orgasm, vaginal lubrication, frequency of sexual desire, enjoyment, arousal, 'tense' feelings, feeling 'close and comfortable with the husband and male husbands' experience of sexual problems, it consist of nine items, the response will be yes (1)or no(2)

The scale include :1 sexual orgasm, 2-vaginal lubrication,3- frequency of sexual desire,4enjoyment,5- arousal, 6-'tense' feelings, 7-feeling 'close 8- comfortable with the husband 9- male husbands' experience of sexual problems).

\section{Tool Validity}

content validity of the study tool was reviewed by jury group that involved three experts in maternity and newborn health nursing for comprehensiveness, accuracy and clarity of language.

\section{Tool reliability}

The internal consistency of the study tool was estimated by using Cronbach's Alpha; and it was 0.791

Practices scoring system

Each practice was scored as (1) for a correct performance and (zero) for an incorrect performance. While the total practices score was calculated as the following: $<60 \%$ was unsatisfactory and if $60 \%$ and more was satisfactory.

\section{Ethical consideration}

To achieve this study, necessery approval was obtained from the responsible authorities of Woman's Health Hospital and Qlta Maternal and Child health Care center. oral consent was obtained from every woman participate in the study after explaining the 
aim and nature of the study. Also, confidentiality was maintained during the research process.

\section{Pilot study}

A pilot study was done on $10 \%$ (50) of women, who used copper IUDs as a family planning method and attended to the family planning outpatient clinic of Woman's Health Hospital and Qlta Maternal and Child health Care center . to assess the tool for its applicability, clarity and to make it obvious to collect data. Data obtained from the pilot were involved to the study sample as no vital modification was done on the tool.

Fram work

Collecting of data took a time of 6 months from the beginning of $9 / 2019$ to the end of 2/2020.

\section{Procedure}

Aims and nature of the study was explained to every woman involved in the study after taking all consents to collect data. The researchers met with women who attended to the family planning outpatient clinic of Woman's Health Hospital (200) and Qlta Maternal and Child health Care center(100) Mabra Hospital (100), and Eleman hosital at Arabeen (100) five days a week from 9:00 AM to 1:00 PM. The researchers interviewed every woman separately to collect data as personal characteristics, obstetric data, current IUDs data, data related to self care practices and presence of infection and data regarding sexual life pattern. Every woman took from 20-30 minute to finish data collection. The researchers then gave the woman a bouchure that contained information regarding copper IUDs as (effectiveness, mechanism of action, advantages, disadvantages, side effects, care while using it)

\section{Statistical design}

Data entry and analysis were done using SPSS version 18 Program statistical software package for social sciences. Data were presented using descriptive statistics in the form of frequencies and percentages. Also, Mean was calculated. Correlation between variables (chi square) were used statistical significance difference was considered at P-value $\leq 0.05$ and highly statistical significance was considered at $\mathrm{P}$-value $\leq 0.01$.

\section{Results}

Table (1): distrubation of studied women according to Personal characteristics of the studied women:n==500

\begin{tabular}{|l|c|c|}
\hline \multicolumn{1}{|c|}{ Personal characteristics } & No. & \multicolumn{2}{|c|}{$\%$} \\
\hline Age: (years) & \multicolumn{2}{|c|}{$29.94 \pm 6.90$} \\
\hline Mean \pm SD & 36 & 7.2 \\
\hline Less than 20 years & 283 & 56.6 \\
\hline 20 - 35 years & 181 & 36.2 \\
\hline More than 35 years & & 44.4 \\
\hline Residence: & 222 & 55.6 \\
\hline Rural & 278 & 18.6 \\
\hline Urban & & 11.2 \\
\hline Level of education: & 93 & 43 \\
\hline Illiterate, read \& write & 56 & 27.2 \\
\hline Basic education & 215 & \\
\hline Secondary & 136 & 66.2 \\
\hline University or higher education & & 33.8 \\
\hline Occupation: & 331 & \\
\hline Housewife & 169 & \\
\hline Employee & & \\
\hline
\end{tabular}

Table (2): distrubation of studied women according to Obstetrical history of the studied women: $\mathbf{n = = 5 0 0}$

\begin{tabular}{|c|c|c|}
\hline \multicolumn{1}{|c|}{ Obstetrical history } & No. & \% \\
\hline Gravidity: & & 9.8 \\
\hline Primi gravida & 49 & 57.6 \\
\hline Multi gravida & 288 & 32.6 \\
\hline Grand multi gravida & 163 & 9.2 \\
\hline Parity: & 46 & 63.4 \\
\hline Primipara & 317 & \\
\hline Multipara & & \\
\hline
\end{tabular}




\begin{tabular}{|l|c|c|}
\hline \multicolumn{1}{|c|}{ Obstetrical history } & No. & \% \\
\hline Grand-multipara & 137 & 27.4 \\
\hline Mode of delivery: & & \\
\hline Normal vaginal delivery & 328 & 65.6 \\
\hline Caesarean section & 172 & 34.4 \\
\hline
\end{tabular}

Table (3): distrubation of studied women according to current Copper IUD used:n=500

\begin{tabular}{|l|c|c|}
\hline \multicolumn{1}{|c|}{ Current Copper IUD data } & No. & \% \\
\hline Duration of use & & 37.4 \\
\hline Less than one year & 187 & 46.2 \\
\hline 1-2 years & 231 & 16.4 \\
\hline More than 2 years & 82 & 70.8 \\
\hline Occurrence of problem while using & 354 & 29.2 \\
\hline Yes & 146 & \\
\hline No & & 24.3 \\
\hline Type of problem & & 75.7 \\
\hline Bleeding between the cycle and the other & 86 & \\
\hline Yes & 268 & 48.6 \\
\hline No & & 51.4 \\
\hline Infection of the reproductive system & 172 & 6.2 \\
\hline Yes & 182 & 93.8 \\
\hline No & & \\
\hline Unexpected pregnancy & 22 & 31.4 \\
\hline Yes & 332 & 68.6 \\
\hline No & & \\
\hline Sexual problems & 111 & 3.1 \\
\hline Yes & 243 & 96.9 \\
\hline No & & \\
\hline Missed IUDs & 11 & 1.7 \\
\hline Yes & 343 & 98.3 \\
\hline No & & 20.1 \\
\hline Ulcer in uterus & 34.7 \\
\hline Yes & 348 & \\
\hline No & 283 & \\
\hline Expulsion & & \\
\hline Yes & & \\
\hline No & & \\
\hline Menorrhagia & & \\
\hline Yes & & \\
\hline No & & \\
\hline
\end{tabular}

Table (4): Distribution of the studied women according to their self-care practices: $==500$.

\begin{tabular}{|l|c|c|}
\hline Self-care practices items & No. & \% \\
\hline Substances used in hygienic care & & 46.8 \\
\hline Clean vulva using hot water only & 234 & 22.6 \\
\hline Clean vulva using ordinary water only & 113 & 30.6 \\
\hline Clean vulva using water + disinfectant & 153 & \\
\hline Types of sanitary pads: & & 19.8 \\
\hline Cotton & 99 & 80.2 \\
\hline Other type & 401 & \\
\hline
\end{tabular}




\begin{tabular}{|l|c|c|}
\hline \multicolumn{1}{|c|}{ Self-care practices items } & No. & \% \\
\hline Types of underwear: & & \\
\hline Cotton & 238 & 47.6 \\
\hline Other type & 262 & 52.4 \\
\hline Method of cleaning the vulval area: & & \\
\hline External by hand & 301 & 60.2 \\
\hline External by gloved hand & 12 & 2.4 \\
\hline By inserting fingers in to vagina & 187 & 37.4 \\
\hline How to clean vulva: & & \\
\hline From up to down & 351 & 70.2 \\
\hline From down to up & 149 & 29.8 \\
\hline
\end{tabular}

\section{Total self-care practices of the studied women}

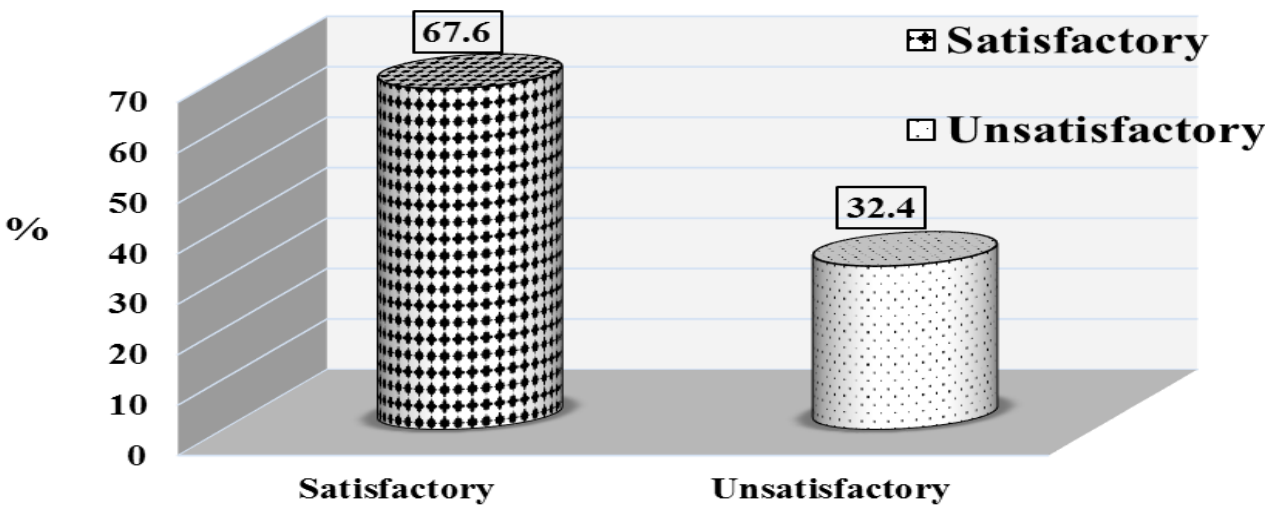

Figure (1): distribution of studied women according to Total self-care practices:n==500

Table (5): Distribution of the studied women according to current sexual life pattern: $n=500$

\begin{tabular}{|l|c|c|}
\hline \multicolumn{1}{|c|}{ Current sexual life pattern } & No. & \% \\
\hline Difference in libido after using IUDs: & & 26.0 \\
\hline Yes & 130 & 74.0 \\
\hline No & 370 & 0.8 \\
\hline Type: & 1 & 71.5 \\
\hline Sexual promiscuity & 93 & 27.7 \\
\hline Complaint from husband & 36 & \\
\hline Complaint from spouses & & 24.4 \\
\hline Difference in sexual desire of husband after using IUDs & & 75.6 \\
\hline Yes & 122 & \\
\hline No & 378 & 78.8 \\
\hline Vagina easily become wet during sexual intercourse & & 21.2 \\
\hline Yes & 394 & 76.4 \\
\hline No & 106 & 23.6 \\
\hline Easily reach orgasm & & \\
\hline Yes & 382 & 20.0 \\
\hline No & 118 & \\
\hline Woman's satisfied at the end of sexual relationship & & \\
\hline Yes & 400 & \\
\hline No & 100 & \\
\hline
\end{tabular}




\begin{tabular}{|l|c|c|}
\hline \multicolumn{1}{|c|}{ Current sexual life pattern } & No. & \% \\
\hline Husband satisfied at the end of sexual relationship & & 73.2 \\
\hline Yes & 366 & 26.8 \\
\hline No & 134 & \\
\hline $\begin{array}{l}\text { Feel uncomfortable or pain during a sexual } \\
\text { relationship }\end{array}$ & & 25.8 \\
\hline Yes & 129 & 74.2 \\
\hline No & 371 & \\
\hline
\end{tabular}

Table (6): Distrubation of studied women according to Relationship between total self-care practices and personal characteristics: $\mathbf{n}=\mathbf{5 0 0}$

\begin{tabular}{|c|c|c|c|c|c|c|}
\hline \multirow{3}{*}{ Personal characteristics } & \multicolumn{4}{|c|}{ Total self-care practices } & \multirow{3}{*}{ Total } & \multirow{3}{*}{ p-value } \\
\hline & \multicolumn{2}{|c|}{ Satisfactory } & \multicolumn{2}{|c|}{ Unsatisfactory } & & \\
\hline & $\mathbf{N}$ & $\%$ & $\mathbf{N}$ & $\%$ & & \\
\hline Age: (years) & & & & & & \multirow{4}{*}{0.310} \\
\hline Less than 20 years & 23 & 63.9 & 13 & 36.1 & $36(100.0)$ & \\
\hline $20-35$ years & 185 & 65.4 & 98 & 34.6 & $283(100.0)$ & \\
\hline More than 35 years & 130 & 71.8 & 51 & 28.2 & $181(100.0)$ & \\
\hline \multicolumn{6}{|l|}{ Residence: } & \multirow{3}{*}{0.127} \\
\hline Rural & 158 & 71.2 & 64 & 28.8 & $222(100.0)$ & \\
\hline Urban & 180 & 64.7 & 98 & 35.3 & $278(100.0)$ & \\
\hline \multicolumn{6}{|l|}{ Level of education: } & \multirow{5}{*}{$0.009 * *$} \\
\hline Illiterate, read \& write & 51 & 54.8 & 42 & 45.2 & $93(100.0)$ & \\
\hline Basic education & 34 & 60.7 & 22 & 39.3 & $56(100.0)$ & \\
\hline Secondary education & 153 & 71.2 & 62 & 28.8 & $215(100.0)$ & \\
\hline University or higher & 100 & 73.5 & 36 & 26.5 & $136(100.0)$ & \\
\hline \multicolumn{6}{|l|}{ Occupation: } & \multirow{3}{*}{0.650} \\
\hline Housewife & 226 & 68.3 & 105 & 31.7 & $331(100.0)$ & \\
\hline Employee & 112 & 68.3 & 57 & 31.7 & $169(100.0)$ & \\
\hline
\end{tabular}

(**) highly statistically significant $p<0.01$

Table (7): Distrubation of studied women according to Relationship between total self-care practices and obstetric history.

\begin{tabular}{|c|c|c|c|c|c|c|}
\hline \multirow{3}{*}{ Obstetric history } & \multicolumn{4}{|c|}{ Total self-care practices } & \multirow{3}{*}{ Total } & \multirow{3}{*}{ p-value } \\
\hline & \multicolumn{2}{|c|}{ Satisfactory } & \multicolumn{2}{|c|}{ Unsatisfactory } & & \\
\hline & $\mathbf{N}$ & $\%$ & $\mathbf{N}$ & $\%$ & & \\
\hline Gravidity: & & & & & & \multirow{4}{*}{0.986} \\
\hline Primi gravida & 33 & 67.3 & 16 & 32.7 & $49(100.0)$ & \\
\hline Multi gravida & 194 & 67.4 & 94 & 32.6 & $288(100.0)$ & \\
\hline Grand multi gravida & 111 & 68.1 & 52 & 31.9 & $163(100.0)$ & \\
\hline \multicolumn{6}{|l|}{ Parity: } & \multirow{4}{*}{0.598} \\
\hline Primipara & 31 & 67.4 & 15 & 32.6 & $46(100.0)$ & \\
\hline Multipara & 219 & 69.1 & 98 & 30.9 & $317(100.0)$ & \\
\hline Grand-multipara & 88 & 64.2 & 49 & 35.8 & $137(100.0)$ & \\
\hline \multicolumn{6}{|l|}{ Mode of delivery: } & \multirow{3}{*}{$0.006 * *$} \\
\hline Normal vaginal delivery & 208 & 63.4 & 120 & 36.6 & $328(100.0)$ & \\
\hline Caesarean section & 130 & 75.6 & 42 & 24.4 & $172(100.0)$ & \\
\hline
\end{tabular}

(**) highly statistically significant $p<0.01$ 
Table (8): Distrubation of studied women according to the relationship between total self-care practices and presence of cervical or vaginal infection:

\begin{tabular}{|l|c|c|c|c|c|c|}
\hline \multirow{2}{*}{\begin{tabular}{c}
\multirow{2}{*}{$\begin{array}{c}\text { presence of cervical or vaginal } \\
\text { infection }\end{array}$} \\
\cline { 2 - 6 }
\end{tabular}} & \multicolumn{4}{|c|}{ Total self-care practices } & \multirow{2}{*}{ Total } & \multirow{2}{*}{ p-value } \\
\cline { 2 - 6 } & $\mathbf{N}$ & $\mathbf{\%}$ & $\mathbf{N}$ & $\mathbf{\%}$ & & \multirow{2}{*}{$\mathbf{0 . 0 0 1 * *}$} \\
\hline Presence of vaginal infection & & & & & & \multirow{2}{*}{$\mathbf{0 . 0 0 1 * *}$} \\
\hline Yes & 89 & 37.4 & 149 & 62.6 & $238(100.0)$ & \\
\hline No & 249 & 95.0 & 13 & 5.0 & $262(100.0)$ & \\
\hline Presence of cervical infection: & & & & & & \\
\hline Yes & 51 & 34.2 & 97 & 65.8 & $148(100.0)$ & \\
\hline No & 287 & 81.5 & 65 & 18.5 & $352(100.0)$ & \\
\hline
\end{tabular}

(**) highly statistically significant $p<0.01$

Table (9): Distrubation of studied women according to the relationship between duration of current IUD used and presence of cervical or vaginal infection:

\begin{tabular}{|c|c|c|c|c|c|c|c|c|}
\hline \multirow{3}{*}{$\begin{array}{l}\text { presence of signs and } \\
\text { symptoms of cervical } \\
\text { or vaginal infection }\end{array}$} & \multicolumn{6}{|c|}{ Duration of IUD } & \multirow{3}{*}{ Total } & \multirow{3}{*}{ p-value } \\
\hline & \multicolumn{2}{|c|}{$\begin{array}{c}\text { Less than } 1 \\
\text { year }\end{array}$} & \multicolumn{2}{|c|}{ 1-2year } & \multicolumn{2}{|c|}{$\begin{array}{c}\text { More than } 2 \\
\text { year }\end{array}$} & & \\
\hline & $\mathbf{N}$ & $\%$ & $\mathbf{N}$ & $\%$ & $\mathbf{N}$ & $\%$ & & \\
\hline \multicolumn{8}{|l|}{$\begin{array}{l}\text { Presence of S\&S of } \\
\text { vaginal infection }\end{array}$} & \multirow{3}{*}{$\mathbf{0 . 0 0 3} * *$} \\
\hline Yes & 54 & 22.7 & 124 & 52.1 & 60 & 25.2 & $238(100.0)$ & \\
\hline No & 133 & 50.8 & 107 & 40.8 & 22 & 8.4 & $262(100.0)$ & \\
\hline \multicolumn{8}{|c|}{ Presence of signs and symptoms cervical infection: } & \multirow{4}{*}{$0.001 * *$} \\
\hline Yes & 23 & 15.5 & 88 & 59.5 & 37 & 25.0 & $148(100.0)$ & \\
\hline No & 164 & 46.6 & 143 & 40.6 & 45 & 12.8 & $352(100.0)$ & \\
\hline Total & 187 & 37.4 & 231 & 46.2 & 82 & 16.4 & $500(100.0)$ & \\
\hline
\end{tabular}

(**) highly statistically significant $p<0.01$

Table (1): Illustrates personal characteristics and reports that $56.6 \%$ of studied women in age group from (20-35) years old with a mean of $29.94 \pm 6.9$, about $55.6 \%$ are from urban area, $43 \%$ of them have a secondary level of education, and $66.2 \%$ of them are housewives.

Table (2): Regarding obstetrics history, this table clarifies that $57.6 \%$ of studied women are multi gravida, $63.4 \%$ of them are multipara, and $65.6 \%$ have a normal vaginal delivery.

Table (3): According to current IUD data, this table reports that $46.2 \%, 70.8 \%$, and $48.6 \%$ of studied women use IUD from 1-2 years, have a problem while using it, and suffer from infection as a side effect while using it respectively.

Table (4): Demonstrates self-care practices of studied women and confirms that $46.8 \%$ clean vulval area using hot warm only. About $80.2 \%$ of them don not use a cotton pad, $52.4 \%$ don not use a cotto underwear, $60.2 \%$ clean their vulval area externally by hand, $70.2 \%$ clean it from up to down.

Figure (1): Shows total self care practices of studied women and reports that $67.6 \%$ of them have a satisfactory practices.
Table (5): Applies distribution of studied women according to presence of cervical or vaginal infection and it is found that $47.6 \%$ of studied women have a vaginal infection, $66.4 \%$ of them complain from redness, secretion and itching. About $29.6 \%$ of them have a cervical infection, from them $54.1 \%$ complain from secretion and pain in pubic area and back.

Table (6): Illustrates the current sexual life pattern of studied women. It is reported that $26 \%$ of women complain from differences in libido after using IUDs, $71.5 \%$ of complaints are from husband, about $24.4 \%$, $21.2 \%, 23.6 \%, 20.0 \%, 26.8 \%$, and $25.8 \%$ of studied women have a difference in sexual desire, Vagina difficult to become wet during sexual intercourse, difficultly reach orgasm, woman's do not satisfied at the end of sexual relationship, husband do not satisfied at the end of sexual relationship, and feel pain during sexual relationship respectivelly.

Table (7): Demonstrates that there is relation between self-care practices of studied women and educatoional level p- value 0.009 and there is no relation between self-care practices and age, residence, and occupation p-value are $0.310,0.127$, and 0.650 respectively.

Table (8): shows relationship between self-care practices and obstetric history and find that there is 
relation between self-care practices and mode of delivery $p$ - value 0.006 , but there is no relation between self-care practices and gravidity and parity p-value are 0.986 and 0.598 respectively.

Table (9): Applies relationship between self-care practices and presence of vaginal or cervical infection, it is found that there is relation between self-care practices and presence of vaginal and cervical infection p- value are 0.001 for both.

Table (10): This table reveals that there is relation between duration of using IUD and presence of vaginal or cervical infection $\mathrm{p}$ - value are 0.003 , and 0.001 respectively.

Table (11): shows relation between duration of using IUD and sexual life pattern, it is reported that there is no relation between duration of using IUD and all items of sexual life pattern, $p$ - value $>0.05$ for all.

\section{Discussion}

About 162 million women (23\% of all contraceptive users) choose IUD as a family planning methods, but using of IUD may be associated by some problems as lack of sexual feeling (Sakinci et al., 2016) and exposure to vaginal infection due to incorrect technique of self care practices (Baraia et al., 2017). this study aimed at assess self care practices and sexual pattern among IUD users. This study aimed to assess self care practices and sexual pattern among IUD users.

The nurse should modify practices to prevent vaginal infection, and this require changes in self care practices that expose woman to risk of infrction (Baraia et al., 2017).

Concerning total self care practices, the present study reported that more than two thirds of studied women have a satisfactory practices while using IUDs as a contraceptive method.

Near to previuos results Wani et al., (2019) who applied their study in Kashmir on health care providers to assess their knowledge, attitudes and practices towards family planning, and found that three quarters of them had a satisfactory practices.

Rephrase in the contrary previous results Baraia et al., (2017) who performed their study in Ismailia city to evaluate the effect of educational program about self care practices on preventing vaginal infection, and illustrated that the great majority of women had insatisfactory practices regarding general hygienic care and personal hygienic care

Also Semachew Kasa et al., (2018) who implemented their study on reproductive age women in Ethiopia to identify knowledge, attitudes and practices towards family planning, and clarified that around one half of studied women had a satisfactory practices. This difference come from working on all family planning methods and not IUDs only.
As regard self care practices of studied women, the current study shows that less than one half of studied women had a correct way of vulval hygienic care and wear a cotton underwear, around two thirds perform the correct method to clean the vulval area, and near to one fifth of them wear a cotton sanitary pads.

Youssef et al., (2019) agreed with previous words, who performed their study on IUD users to assess their feminine hygiene and sexual function, and reported that around one half of studied women follow the correct way and method of vulval hygienic care and wear a cotton underwear and more than one fifth of them wear a cotton sanitary pads.this similarity come from working on the same countery and on the same study sample (IUDs users) and under the same circumstances.

IUDs considered one of the most popular long term reserviable family planning methods. Genital infection related to using IUDs is generally low, but the rate of infection may expected to increase by the effect of imbalance in the bacterial flora due to prolonged IUDs using (Kanakannavar \& S., 2019).

As regard presence of genital infection during IUDs using, present study revealed that less than one half of IUDs users complained from vaginal infection and less than one third had a cervical infection.

On the same line, Youssef et al., (2019) who clarified that less than one half of studied women had a vaginal infection and less than one third had a cervical infection. Also Martins et al., (2016) who implemented their study to identify the risk of genital infection in women using IUDs, and reported that around one third of IUDs users had vaginal infection.

On the other hand Aoun et al., (2014|) who applied their study to assess relation between age, parity, and IUDs type and complication and discontinuation of IUDs, and showed that less than one quarter of studied women had vaginitis and only $6 \%$ complained from cervicitis.

Also Rezk et al., (2017) who performed their study to assess risk of genital infection among new users of COCS and LNG-IUS, and clarified that less than one quarter of studied women had bacterial vaginosis. This difference back to using of LNG-IUS instead of copper IUDs.

Contraceptive as IUD can improve women's and puplic health, but many women terminate this method due to dissatisfaction that caused by its effect on sexual life (Sanders et al., 2018).

According to sexual life pattern among IUD users, the actual study revealed that around one quarter of IUD users complained from problem in sexual pattern as (difference in libido, different in sexual desire, vaginal difficult to get wet, difficult reach orgasm and pain during sexual relation). 
In agreement with previuos words Umran (2016) who carried out their study to evaluate the effect of contraceptive method on the function of female sex, and found that around one quarter of studied women had a dyspareunia and sexual problem in partener.

Also near to previous word Higgins \& Smith (2016) who applied their study to identify women`s sexual function, satisfaction, and perception, after using long term reversible contraceptive method, and showed that around one fifth of studied women complained from change in sexual pattern.

Disagreement with previous Turan et al., (2020) who worked to assess the effect of levenorgestral-releasing IUDs on female sexual function, and reported that around one half of studied women had a dysfunction in lubrication, orgasm and sexual pain, and this ocurr due to difference in type of IUD used.

As regard current IUD data, the present study revealed that less than one half of IUDs users, their duration of IUDs insertion from 1-2 years, more than two thirds have a problem while using it, and bleeding is the most occurring problem by around one quarter of all problems.

Also Aoun et al., (2014) had the same openion, who implemented their study to assess effect of age, parity and device type on complication and termination of IUDs, and clarified that less than one quarter of IUDs users complained from bleeding as a complication.

On contrast, Wright et al., (2014) who performed their study on cervical ectropin and IUDs, and showed that only $6.5 \%$ of studied women complained from bleeding as a complication. This difference caused by difference in study`s design as it was a retrospective study, and not follow all IUDs users, but deal with client sheet during follow up.

According to relation between self care practices and personal data and parity, the actual study shows that there is relation between self care practices and eduational level and no relation between it and age, occupation and parity.

Semachew Kasa et al., (2018) illustrated that there are relation between practices and educational level, but Wani et al., (2019) found no relation between practices and educational level and there was relation between practices and age and parity. This dissimilarity caused by applying of their study on all types of family planning methods and not IUDs only. Regarding self care practices and its relation with occurance of genital infection, present study reported that there is relation between self care practices and occurance of vaginitis and cervitis. The same openion had from Youssef et al., (2019) who illustrated that there was relation between self care practices and occurance of genital infection.
The prolonged use of IUDs can make changes in the vaginal bacterial flora, enabling the spread of anaerobic microorganisms as Gardnerella vaginalis, predisposing to occurance of bacterial vaginosis (Martins1 et al., 2016).

Current study releaved that there is relation between duration of IUDs and occurance of vaginal and cervical infection. These words was agreed with Kanakannavar \& S., (2019) who worked on clinicomicrobiological study of the removed IUD, and clarified that there was relation between duration of IUDs and positive culture for infection.

Also Achilles et al., (2018) who applied their study to assess the impact of contraceptive initation on vaginal microbiota, and Martins et al., 2016, who performed their study to identify the risk of genital infection in women using IUDs, these two studies agreed with previous words.

But Aoun et al., (2014) had another openion, who showed that no relation between vaginal and cervical infection and duration of IUDs.

Present study reported that there is no relation between duration of IUDs and sexual life pattern. On the same line Nurvita et al., (2018) who implemented their study to identify female sexual function in women using hormonal and non hormonal contraception, and clarified that there was relation between sexual function and IUD. Also Aoun et al., (2014) agreed with this.

Regarding personal data and parity, the actual study found that around one half of studied women in age group 20-35 years, from urban, have a secondary level of education, and are housewives

Also Aoun et al., (2014) \& Saidu et al., (2017) who implemented their study in Nigeria to determine the type of IUDs that is less associated with genital infection, and clinical features seen among IUD susers. Both of them agreed with previous words. But Umran (2016) Kanakannavar \& S., (2019) had diferent openion. And this diference back to working on other points difere from actual study.

\section{Conclusion}

This study revealed that women had insufficient self care practices regarding IUDs and there have some form of sexual pattern affected by using IUDs as a contraceptive method.

\section{Recommendation}

Educational program about self care practices and sexual pattern for IUD users should be provided to both health care providers and clients.

Counseling of women about Sexual acceptability should take more attention from health care provider . 
Repeatation of this research on a large sample size and other professional hospitals for generalization of results.

\section{Acknowledgment}

The authors would like to convey special thanks to all pregnant women included in the study and to all individuals help the researchers in the data collection.

\section{References}

1. Achilles, S., Austin, M., Meyn, L., Mhlanga, F., Chirenje, Z., \& Hillier, S., (2018): Impact of contraceptive initiation on vaginal microbiota. American Journal of Obstetrics and Gynecology, 218(6), 622.e1-622.e10. https://doi.org/10.1016/j.ajog.2018.02.017

2. Aoun, J., Dines, V., Stovall, D., Mete, M., Nelson, C., \& Gomez-Lobo, V., (2014): Effects of age, parity, and device type on complications and discontinuation of intrauterine devices. Obstetrics and Gynecology, 123(3), 585-592. https://doi.org/10.1097/ AOG.0000000000000144.

3. Banaei M., Alidost, Ghasemi E., Dashti S.. (2020): A comparison of sexual function in primiparous and multiparous women. Journal of Obstetrics and Gynaecology 40:411-418.

4. Baraia, Z., Abdallah, I., \& Nour, S., (2017): Impact of Educational Program about Selfcare Practices on the Reliving of Vaginal Infection among High Risk Women in Ismailia City. IOSR Journal of Nursing and Health Science, 06(03), 73-78. https://doi.org/10.9790/1959-0603077378

5. Brown Health services (2019): Intrauterine Device ( IUD ) Aftercare Instructions. 3953(August).

6. Egypt FP2020 Commitment, (2020): Egypt's family planning policies tested by COVID-19, Available https://www.familyplanning2020.org/egypt

7. Higgins, J., \& Smith, N., (2016): The Sexual Acceptability of Contraception: Reviewing the Literature and Building a New Concept. Journal of Sex Research, 53(4-5), 417-456. https://doi.org/10.1080 /00224499.2015.1134425

8. Igbaria, M., Iivari, J., Community, F., Sciences, H., Of, D., Mobile, A., Diabetes, P., Of, P., Ho, T., Chipps, P., Asiri, H., Skinner, A., Yorke, E., Atiase, Y., Bryman, A., Bell, E., Stausberg, M., Kanakannavar, S., \& S., (2019): Clinicomicrobiological study of the removed intrauterine device. International Journal of Reproduction,
Contraception, Obstetrics and Gynecology, 8(5), 2011. https://doi.org/ 10.18203/23201770.ijrcog20191959

9. Martins1, G., Junior, J., Tomaz, T., Andrade, C., de, \& Campos, W., (2016): The risk of genital infections in women using intrauterine device. DST - J Bras Doenças Sex Transm, 28(2), 61-63. https://doi.org/10.5533/DST-2177-8264201628205

10. McNany, E., (2017): Copper intrauterine device. Primary Care Procedures in Women's Health, 121-134. https://doi.org/10.1007/9780-387-76604-1_11

11. Nurvita, D., Effendi, I., Sukatendel, K., Salim, H., Lintang, L., \& Adella, C., (2018): Female Sexual Function in Women Using Hormonal and Non- hormonal Contraception. 17(11), 58-63. https://doi.org/10.9790/08531711015863

12. Pollack, A., Ross, J., \& Perkin, G., (2016): Intrauterine Devices (IUDs) in Developing Countries: Assessing Opportunities for Expanding Access and Use. Hewlett Foundation Menlo Park, California, United States.

13. Reproductive Heath Access. (2017): IUD Fact Sheet. March. https://www.reproductiveaccess.org/wpcontent/uploads/06/IUD_facts pdf.

14. Rezk Mohamed, Tarek Sayyed, Alaa Masood \& Ragab Dawood (2017): Risk of bacterial vaginosis, Trichomonas vaginalis and Candida albicans infection among new users of combined hormonal contraception vs LNGIUS, The European Journal of Contraception \& Reproductive Health Care, 22:5, 344-348, DOI: 10.1080/13625187.2017.1365835

15. Saidu, A., Tunau, K., Panti, A., Nwobodo, E., Mohammed, Y., Amin, J., \& Garba, J., (2017): Effect of hormonal and copper IUDs on genital microbial colonisation and clinical outcomes in North-Western Nigeria. International Journal of Reproduction, Contraception, Obstetrics and Gynecology, 6(6), 2143. https://doi.org/10.18203/23201770. ijrcog 20172304

16. Sakinci, M., Ercan, C., Olgan, S., Coksuer, H., Karasahin, K., \& Kuru, O., (2016): Comparative analysis of copper intrauterine device impact on female sexual dysfunction subtypes. Taiwanese Journal of Obstetrics and Gynecology, 55(1), 30-34. https://doi.org/ 10.1016/ j.tjog.2014.12.011

17. Sanders, J., Higgins, J., Adkins, D., Stoddard, G., Gawron, L., \& Turok, D. K. 
(2018): The Impact of Sexual Satisfaction, Functioning, and Perceived Contraceptive Effects on Sex Life on IUD and Implant Continuation at 1 Year. Women's Health Issues, 28(5), 401-407. https://doi.org/10.1016/j.whi.2018.06.003

18. Semachew Kasa, A., Tarekegn, M., \& Embiale, N., (2018): Knowledge, attitude and practice towards family planning among reproductive age women in a resource limited settings of Northwest Ethiopia. BMC Research Notes, 11(1), 7-12. https://doi.org/10.1186/s13104-018-3689-7

19. Turan, G., Yalcin Bahat, P., Aslan Cetin, B., \& Peker, N., (2020): The effect of a levonorgestrel-releasing intrauterine device on female sexual function. Journal of Obstetrics and Gynaecology, $0(0), \quad 1-6$. https://doi.org/10.1080/01443615.2020.17556 30

20. Umran, O., (2016): Effect of the Contraceptive Methods on Female Sexual Function. International Journal of Caring Sciences, 9(3), 997.

21. Vigersky, R., Choolani, M., (2019): WHO consolidated guideline on self-care interventions for health: sexual and reproductive health and rights. In Omega (Vol. 23, Issue 3). https://doi.org/CC BY-NC-SA 3.0 IGO

22. Wani, R., Rashid, I., Nabi, S., \& Dar, H., (2019): Knowledge, attitude, and practice of family planning services among healthcare workers in Kashmir - A cross-sectional study. Journal of family medicine and primary care, $8(4)$, 1319-1325. https://doi.org/10.4103/jfmpc. jfmpc_96_19.

23. Wright, K., Mohammed, A., SalisuOlatunji, O., \& Kuyinu, Y., (2014): Cervical Ectropion and Intra-Uterine Contraceptive Device (IUCD): A five-year retrospective study of family planning clients of a tertiary health institution in Lagos Nigeria. BMC Research Notes, 7(1), 1-6. https://doi.org/10.1186/1756-0500-7-946

24. Youssef N., karam, ELDean H. Alam, Ahmed N., Hussien\& Mostafa N., Elh., (2019): assessment of feminine hygiene and sexual function among intra uterine device users. Assiut Scientific Nursing Journal, 7(18), 180-191. 